\title{
La recepció de Tirant lo Blanch a la València dels segles XIX i XX
}

\author{
The Reception of Tirant lo Blanch in Valencia in the 19th and 20th Centuries
}

\author{
Rafael Roca \\ (Universitat de València)
}

\begin{abstract}
RESUM
Durant la segona meitat del segle XIX els intel.lectuals valencians manifestaren un notable interés per les principals obres del Quatre-cents, entre les quals la novel.la Tirant lo Blanch, que, en no haver sigut editada en català durant l'Edat Moderna, fins a 1873 pràcticament només fou accessible per a bibliotecaris i erudits. Així, l'article repassa els esforços d'aproximació, divulgació i estudi que, amb la inestimable ajuda del mallorquí Marià Aguiló, entre 1866 i 1928 realitzaren els escriptors valencians vinculats al moviment de la Renaixença per tal de valorar i reivindicar l'obra de Joanot Martorell; i els situa com el primer pas d’un llarg procés de recuperació que s'estengué al llarg de tot el segle XX.
\end{abstract}

\section{Paraules Clau}

Tirant lo Blanch, Renaixença, València, segles XIX-XX, Marià Aguiló.

\begin{abstract}
During the second half of the 19th century Valencian intellectuals showed a remarkable interest in the major works of the 15th century among which we find Tirant lo Blanch, a novel which was not published in Catalan during the Modern Age until 1873, and therefore was only accessible to librarians and scholars. This article reviews the efforts, with the invaluable help of the Majorcan Marià Aguiló, made by Valencian writers between 1866 and 1928 to approach, reveal and study the matter. These authors' aim, related to the Renaixença movement, was to value and demand a reappraisal of Joanot Martorell's work; and so, they took the first step in a long process of cultural recovery which stretched on for the whole of the 20th century.
\end{abstract}

\section{KEYWORDS}

Tirant lo Blanch, Renaixença, València, 19th and 20th Centuries, Marià Aguiló.

Rebut: $15 / 09 / 2020$

Acceptat: 14/10/2020 


\section{La fascinació pel passat medieval}

La influència que el Romanticisme va exercir sobre els protagonistes de l'anomenada Renaixença, el moviment lingüístic i literari que hegemonitzà el conreu de les lletres als territoris de llengua catalana durant la segona meitat del segle XIX -i que troba els seus correlats en iniciatives culturals europees com ara el Rexurdimento gallec i il Risorgimento italià-, va despertar un creixent interés pel passat medieval, que, en bona part idealitzat, als ulls dels escriptors coetanis es presentava com a refulgent.

Així, des d'una data molt inicial, els lletraferits catalanoparlants de la segona meitat del Vuitcents (i, singularment, els valencians) es varen adonar que era a l'època medieval -a l'esplendorós segle $\mathrm{XV}$, sobretot- on calia cercar els models i referents més vàlids per a la recuperació no sols lingüística i literària sinó també identitària que pretenien portar a terme. Una identitat, de fet, per aquell temps considerablement diluïda dins del marc polític espanyol.

A aquesta fascinació hi contribuí, d'una manera notòria, el fet que, entre els autors i les obres que es varen produir a la Corona d'Aragó durant segles XIII, XIV i XV, els escriptors del Vuitcents hi trobaren tant les arrels i la magnificència de la llengua i literatura catalanes que, des d'un punt de vista cultural -no polític-, desitjaven restaurar, com el que ells mateixos anomenaven «les glòries antigues». És a dir, el regne autònom que el territori valencià va ser un dia $\mathrm{i}$, des de segles enrere, havien definitivament «perdut»; i que, per tal de ser «tolerat», «permés», es mostrava com un record nostàlgic i innocu davant del poder polític espanyol.

A més, en el món medieval els escriptors del segle XIX buscaven també un fil d'unió i d'inspiració que, a la vegada, els distanciara dels literats immediatament precedents -els de l'Edat Moderna, considerats com els responsables de la mal anomenada «decadència» de la literatura catalana- i els enllaçara, mitjançant una comunió gairebé mística, amb els grans autors clàssics del Quatre-cents.

Així ho afirmava en 1885 un dels principals escriptors vuitcentistes, Teodor Llorente i Olivares, líder de la branca valenciana de la Renaixença, quan, evocant els seus inicis literaris i l'estada com a bibliotecari de la Universitat de València -durant el període 1858-1861- del mallorquí Marià Aguiló i Fuster, rememorava com ell i d'altres companys d'estudis es complaïen a visitar la biblioteca universitària, on sempre trobaven el seu mestre, Aguiló,

restablint lo texto alterat d'una esparsa d'Ausiàs March, investigant l'orige llegendari de les gestes de Tirant lo Blanch, buscant les costums d'altra etat en les satíriques cudolades de Jaume Roig, o sa fe vivíssima en les cansons místiques de Corella (Llorente, 1885: 7).

La consciència i la constància d'un passat literari esplèndid, lluminós, hi eren, i només calia submergir-se en el seu descobriment i divulgació, una tasca certament àrdua i complicada per al moment històric i cultural en què ens situem, tenint en compte les característiques que presentava la societat valenciana de la segona meitat del segle XIX, majoritàriament esquiva, quan no obertament contrària, al ressorgiment identitari propi - dit amb unes altres paraules: cofoia amb el marc cultural i polític que li oferia l'estat espanyol-; i, singularment, esquerpa envers el conreu escrit d'una llengua -la catalana - que, si bé era viva i habitual en els usos informals i casolans, era considerada indigna i difunta per als cultes.

Amb tot, i malgrat aquestes i d'altres dificultats socials i tensions polítiques -palpables així que, per exemple, llegim els discursos d'obertura de curs de la societat cultural Lo Rat Penat, en 
què els seus responsables sentien la necessitat de justificar que no perseguien cap finalitat política separatista-, resulta indubtable que els escriptors valencians del Vuit-cents portaren a terme una recuperació de les grans obres i escriptors medievals que podrà ser tan tímida o raquítica com vulguem, però real.

De fet, en els darrers anys hem tingut ocasió de comprovar com un dels personatges més reivindicats per aquells escriptors fou el rei En Jaume, autor d'una de les grans cròniques medievals catalanes -la coneguda com a Llibre dels Feits-, en qui els protagonistes de la Renaixença valenciana veien personificada la pàtria -és a dir, l'antic Regne de València-, i la memòria del qual restabliren i mitificaren bàsicament a través de tres fites: 1) la commemoració del VIé centenari de la seua mort, que tingué lloc en juliol de 1876; 2) la visita que una trentena d'escriptors i artistes valencians i catalans realitzaren en maig de 1882 al monestir de Poblet (Tarragona), el lloc on fou enterrat Jaume I; i 3) la celebració del VII é centenari del naixement del Conqueridor, que, malgrat l'oposició política dels republicans blasquistes, aleshores majoritaris a l'ajuntament del cap-i-casal, es portà a terme a València en 1908 (Roca, 2012).

Així mateix, un dels escriptors medievals més aclamat durant la segona meitat del segle XIX fou Ausiàs March (Roca, 2018), de qui en els darrers temps hem tingut ocasió de comprovar que en 1860, a l'entorn de la celebració del IV centenari de la seua defunció, l'Ajuntament de València posà en marxa un projecte d'edició de les seues poesies que, «por cosas valencianas largas de contar», en expressió del mallorquí Marià Aguiló, no arribà a rams de beneir (Tomàs, 2012: 43-44).

D'una altra banda, sabem que també hi fou reivindicat l'altre gran poeta valencià del segle XV, Joan Roís de Corella, l'inici de la recuperació del qual cal situar precisament en el darrer terç del Vuit-cents, i de qui en els últims anys hem pogut documentar que en 1870 Vicent Wenceslau Querol i Marià Aguiló tenien el projecte editar les seues obres -en aquell moment encara inèdites- recollides en el conegut com a manuscrit Maians (Roca, 2013: 743-744). I també disposem de noves i aclaridores informacions respecte al procés de localització i difusió de la novel.la de cavalleries Curial e Güelfa, que diversos protagonistes de la Renaixença portaren a terme durant el període 1876-1901 (Roca, 2019).

\section{El darrer terç del segle XIX}

Pel que fa a l'interés que els intel.lectuals valencians vuitcentistes manifestaren per la recuperació de les obres i els escriptors del segle $\mathrm{XV}$, resulta evident que no podia passar-los desapercebuda una novel.la tan peculiar i emblemàtica com el Tirant lo Blanch. I així comprovem que, l'1 de setembre de 1866 i sota el títol de «Breve historia y justos deseos sobre un notable libro», el diari Las Provincias, fundat en gener d'aquell any per Teodor Llorente, publicava un article dedicat a la novel.la de Joanot Martorell que estava signat per l'historiador Domènec Andrés Sinisterra, conegut per haver estat l'autor d'un opuscle sobre l'enderrocament de les muralles de València (Andrés, 1866).

En referència al Tirant, Andrés Sinisterra explicava que, d'aquesta «famosa» $\mathrm{i}$ «curiosa obra en lemosín» -terme amb què els vuitcentistes es referien al català culte-, només se'n conservaven tres exemplars: «uno de la biblioteca del Vaticano», «otro de Oporto» i el que pertanyia a la Universitat de València, que «lo guarda - puntualitzava- cuidadosamente encerrado en una caja en el mejor estado de conservación». Així mateix, també assenyalava la seua data d'impressió, dimensions -«cuarto mayor, muy abultado»-, tipus de paper i tipografia; «de modo -assegura- 
va- que todos sus capítulos pueden fácilmente leerse aun por personas poco versadas en la paleografía y práctica en la lectura de letra antigua». I encara afegia d'altres detalls descriptius, com ara la seua puntuació «especial», els tipus de guions -«vírgulas oblicuas »-, i la manca de portada i de numeració en les pàgines (Andrés, 1866).

Pel que fa al contingut del Tirant, Andrés Sinisterra únicament remetia al «aventajado concepto que mereció al celoso cura del lugar del ingenioso D. Quijote». Aquest laconisme, però, no ens ha de resultar estrany, ja que, acte seguit, confessava que: «desgraciadamente, nosotros todavía no hemos podido tener el gusto ni la oportunidad de saborear estos gratos pasatiempos en nuestra biblioteca»; és a dir, que no havia llegit l'obra. Això no obstant, és més que evident que valorava notablement el Tirant lo Blanch; i que fins i tot anhelava que «llegue el dichoso día en que se multiplique y reimprima». Cosa a la qual, sens dubte, devien al.ludir els «justos deseos» anunciats en el títol de l'article (Andrés, 1866).

En aquesta línia, en la de reclamar una nova edició de la novel.la de Martorell -recordem que l'última en català era de 1497 (Escartí 2010)-, Andrés Sinisterra finalitzava el seu escrit assegurant que:

el ilustrado y conocido bibliógrafo D. Mariano Aguiló, bibliotecario que fue de esta Universidad, tiene el noble propósito, que aplaudimos, de procurar que esta necesidad, que con nosotros sentirán muchos, pueda llenarse fácil y cómodamente. A este objeto está preparando hace tiempo una nueva edición de aquel raro libro, en la que trata de conservar hasta la misma forma gótica de sus tipos, puntuación y distribución, para que sea a la vez un monumento universal del estado de la primitiva tipografía en nuestra patria (Andrés, 1866).

$\mathrm{Al}$ respecte, cal recordar que, efectivament, des de la seua estada com a bibliotecari de la Universitat de València -o des de l'inici de la dècada dels anys seixanta, com a mínim-, Aguiló treballava en una edició del Tirant lo Blanch que, finalment, es materialitzà en quatre volums que veieren la llum entre 1873 i 1905. I que, des de 1866 fins a 1868, si més no -i per encàrrec d'Aguiló-, el català Josep Roca i Ruscalleda, que aleshores exercia com a docent a la ciutat de València, es va dedicar a copiar les parts i fragments de l'exemplar del Tirant custodiat a la Universitat de València que li indicava el mallorquí.

Així es pot comprovar a les cartes que Josep Roca envià a Marià Aguiló durant aquells anys, i que es conserven inèdites a la Biblioteca de Catalunya. Una tasca, la de copista, en la qual sembla que participaren dues persones més, com a mínim: un altre mestre català anomenat Viñas i un estudiant de magisteri del qual no s'explicita la identitat. I un treball que fou criticat per l'estudiós Joan Givanel i Mas, que durant la seua intervenció en el Primer Congrés Internacional de la Llengua Catalana (1906) afirmà:

Qui com jo ha cotejat el text que de la celebrada producció de Johanot Martorell, Tirant lo blanc, publicà D. Mariàn Aguiló y Fuster, ab l'edició impresa a Valencia per Nicolás Espindeler, l'any de 1490, pot dir ben alt qu'entre un y altre text hi figuren més de 800 variants. [...] Hi han moltes llibertats que's va prendre'l copista, llibertats que no són pròpies en una obra destinada exclusivament als estudiosos (Givanel 1906: 543-544).

D’aquesta manera, és molt probable que les errades o divergències -o «llibertats», com les anomena Givanel- siguen conseqüència de dues circumstàncies: en primer lloc, la multiplicitat 
i diversitat de mans segurament no expertes, amateurs, que participaren en la còpia del Tirant lo Blanch; i en segon, que, tal com afirmà Josep Ribelles Comín en 1915: «Aguiló copió de ambas ediciones: de la de València de 1490 y de la de Barcelona de 1497» (Ribelles 1915: 434).

Tornant a l'anunci o «revelació» que, en 1866, realitzà en la premsa diària Andrés Sinisterra -ja que desconeixem fins a quin punt en aquell any era públic que Aguiló treballava en una edició del Tirant-, cal dir que l'erudit mallorquí començà la succinta «Nota» que encapçala el seu Libre del valerós e strenu caualler Tirant lo Blanch de la següent manera:

No podíem pensar en la publicació d'una Biblioteca Catalana sense fer esment de la famosa obra den Johanot Martorell de que tants parlen y que tant pochs han pogut llegir almenys en son text original. Una pila ens hi empenyien y fins n'hi va haver que l'anunciaren per comprometrens a publicarla (Aguiló 1873-1905: V);

unes paraules que, molt probablement, amagaven el ressò de les que varen ser publicades a Las Provincias.

Per a finalitzar amb l'article periodístic que ens ocupa, cal destacar que l'autor també afirmava que «sentiríamos vivamente que siendo Valencia donde se conserva el original [del Tirant lo Blanch], escrito por autores hijos de esta ciudad, [...] fuera preferida para su reimpresion Barcelona» (Andrés, 1866), com finalment així fou. D’aquesta manera, Andrés Sinisterra recordava amb recança que era a la Ciutat Comtal on, poc temps abans, havien sigut impreses diverses obres d'accent valencià, com ara el Llibre de les dones de Jaume Roig (editat en 1865 per Francesc Pelai Briz), les obres del bisbe Costa i Borràs (publicades en 1866 per Ramon de Ezenarro), «y otras de diferentes valencianos insignes». «Si bien es cierto», reconeixia a la fi, «que por tales publicaciones solo podemos culpar á nuestra incuria» (Andrés, 1866). És a dir, a la desídia que, en qüestions històriques i culturals, sovint manifestaven els valencians envers tot allò referent a la cultura i la història pròpies.

En resposta a l'article d'Andrés Sinisterra, dues setmanes després el Diario Mercantil de Valencia en publicava un altre sense signar que, tanmateix, sabem que fou redactat per Josep Maria Torres Belda (1833-1884), bibliotecari de la Universitat i cronista de la ciutat de València que, amb el pas dels anys, esdevingué un dels més autoritzats erudits de la branca valenciana de la Renaixença. Així, en la carta que aquell mateix dia, 15 de setembre de 1866, Josep Roca remeté a Marià Aguiló podem llegir:

Le hubiera escrito mas pronto, y dos razones han sido causa de la demora. $1^{a}$, porque creía que antes de mucho tendriamos local-escuela y casa fija que á estas horas áun esperamos; 2a, porque sabia que se iba á escribir algo sobre el «Tirant», y luego de publicarse este primer escrito, me manifestó uno de los bibliotecarios que quería rectificar lo publicado con un segundo artículo, cuya aparición en los diarios he esperado, y tengo el gusto de remitirselos inclusos á V. El primero [...] se insertó en el diario «Las Provincias» [...] y el $2^{\circ},[\ldots]$ debido á la pluma del bibliotecario de quien antes le he hablado (creo que se llama José Torres, quien dice no tiene el honor de conocerle a V.), lo ha publicado el diario «El Diario Mercantil» del dia de hoy ${ }^{1}$.

Efectivament, tal com s'hi anunciava des del principi, aquell article era una rèplica o rectificació del d'Andrés Sinisterra. En conseqüència, a propòsit del Tirant lo Blanch, que qualificava 
com «la joya mas preciada de esta biblioteca [universitaria]», Torres anunciava que «vamos á ampliar un poco las noticias que el autor de cierto artículo insertó en Las Provincias, [...] deshaciendo de paso algunos errores en que ha incurrido» (Torres, 1866). I el primer que proclamava era que «es dudoso que el Tirant fuese escrito en lemosín por los indicados [Joanot Martorell i Martí Joan de Galba]», tal com havia assegurat Andrés Sinisterra; ja que, continuava Torres, com pot llegir-se al final de la novel.la, «el Tirant fue traducido al lemosín, ó mejor dicho, reducido á vulgar lengua valenciana, de la lengua portuguesa» (Torres, 1866). Era així com el bibliotecari de la Universitat de València donava carta de validesa a determinades teories, com ara la del cervantista Diego Clemencín, qui havia afirmat que:

considerando la semejanza que hay en la composición y estilo de la cuarta parte con las tres primeras, es muy verosímil que todas fueran originalmente de una misma mano, y como la traducción de Galba se hizo, segun suena, del portugués, puede creerse que el Tirante existió íntegro en este idioma (Torres, 1866).

Una altra de les esmenes que realitzava Josep $M$. Torres respecte al que quinze dies abans havia afirmat Andrés Sinisterra afectava a la quantitat d'exemplars coneguts del Tirant lo Blanch, que en la seua opinió no n'eren tres, sinó quatre. D’aquesta manera, assegurava que, a més dels conservats a València, a la biblioteca d'Oporto «y el que se dice proceder de la del Vaticano, [que] existe en la Sapienza de Roma, posee otro el museo británico de Londres, que se dice ser el mas completo de los cuatro hoy día conocidos» (Torres, 1866).

De passada, el bibliotecari també es mofava d'Andrés Sinisterra: «Ignorábamos que la paleografía y práctica en la lectura de letra antigua -entre lo cual no sabemos qué distinción hará el articulista- se aplicase á la lectura de los libros impresos». I qualificava de «descripción [...] muy inexacta» la que, de l'incunable, n'havia realitzat l'articulista de Las Provincias Andrés Sinisterra. En conseqüència, Torres en feia una de nova en què, per exemple, assenyalava que «la impresion es esmerada; la tinta escelente y de un hermoso negro; los márgenes espaciosos, y las letras capitales, de regulares dimensiones »; i destacava que, en la primera pàgina del segon quadern:

en el espacio que media entre las cabezas y piés de los leones, y rodeando el escudo se nota una faja que contiene el nombre de «Nicolaus Spindeler», célebre tipógrafo que trabajó en Barcelona y Valencia, y de cuya prensa salió el raro libro que nos ocupa (Torres 1866).

Posteriorment, encara al.ludia al famós judici que, sobre el Tirant lo Blanch, recull la novel.la cervantina -i que havia sigut reproduit per Andrés Sinisterra-; i afirmava que «no todos los distinguidos críticos y comentadores del Quijote están conformes en apreciar de un mismo modo el sentido en que Cervantes quiso espresarse»; i que, si bé Pascual Gayangos «se inclina á creer que su intención fue elogiarle», «el Sr. Clemencín fue de contrario parecer en la interpretación de dicho pasage $\gg$ (Torres, 1866). Finalment, el bibliotecari tancava el seu llarg article reproduint la negativa opinió que el Tirant meresqué a l'humanista valencià Joan Lluís Vives, que a l'obra $D e$ institutione faeminae christianae (1523) escrigué (traduïm del llatí): «Així com [haurien d'ocupar-se] dels llibres perniciosos, com són, a Espanya, Amadís, Esplandià, Florisand, Tirant i Tristà, les estupideses dels quals no tenen fi, a diari n'ixen de noves».

L'interés de Josep M. Torres per una obra de les característiques del Tirant lo Blanch -de la qual devia tenir un profund coneixement arxivístic- no finalitzà amb aquell article. I així sabem 
que, vuit anys després, en desembre de 1874, s'hi referí novament en el transcurs d'una memòria sobre els orígens de la impremta a València, amb què obtingué un dels premis del certamen que convocà l'Ateneu Literari a propòsit del IV centenari de la primera obra impresa ${ }^{2}$. Tot sembla indicar que, en aquell treball, que finalment romangué inèdit, el bibliotecari de la Universitat de València reproduïa diversos documents referents al contracte signat amb Nicolau Spindeler per tal que estampara l'edició princeps del Tirant lo Blanch. Uns documents que, segons afirmà trenta anys després Àngel Aguiló, fill de Marià Aguiló,

[Torres] los envià generosament al meu Pare (q. a. c. s.) en carta de 31 d'Agost de 1874 per si'ls volía col-lacionar a les notes que preparava per aquest volum. No cal dir -continuava Àngel Aguiló- si regracià tant valiosa ofrena, y que los hauríam copiat ací a no haverlos publicat lo senyor Serrano Morales en l'article referent a Spindeler (p. 529-531) de son Diccionario de Impresores Valencianos (Aguiló, Àngel 1873-1905: IX-X);

una magna obra, la de Serrano Morales, el títol exacte de la qual és Reseña histórica en forma de diccionario de las imprentas que han existido en Valencia desde la introducción del arte tipográfico en España hasta el año 1868, con noticias bio-bibliográficas de los principales impresores, i que fou guardonada durant l'edició dels Jocs Florals de València de $1893^{3}$.

Els documents a què es referia Àngel Aguiló, per tant, deuen ser els cinc que Serrano Morales copià i comentà mínimament, i el primer dels quals qualificà com a «interesantísimo [...] porque nos da á conocer el número de ejemplares que se imprimieron del Tirant lo Blanch y las condiciones con que se editó » (Serrano, 1898-1899: 528). Pel que fa als quatre restants, cal dir que fan referència al contracte d'edició i a les diverses quantitats que Spindeler rebé de Joan Rix de Cura a compte de la impressió del Tirant lo Blanch.

Finalment, cal assenyalar que Serrano (1898-1899: 532-533) també inclogué a la seua obra una descripció formal de l'exemplar del Tirant lo Blanch conservat a la Biblioteca de la Universitat de València.

\section{Les primeres dècades del segle $\mathrm{XX}$}

Amb el canvi de segle, l'interés dels escriptors valencians per la novel.la de Martorell no feu sinó acréixer-se. Així, deixant de banda les tres conferències que, sobre el Tirant lo Blanch, organitzà la societat cultural Lo Rat Penat en els anys 1912, 1919 i 1921 -i de les quals em vaig ocupar en: Roca 2017-, cal destacar que el 18 de febrer de 1913 el diari Las Provincias publicà un extens article titulat «El incunable Tirant lo Blanch», que estava signat per Juan de Antaño, pseudònim

2. A la crònica del certamen que, amb el títol «Celebración del cuarto centenario de la introducción de la Imprenta en Valencia, el 20 de diciembre de 1874», publicà el diari Las Provincias (22-XII-1874) podem llegir: «El premio de socio de mérito, ofrecido al autor de la mejor Memoria sobre los orígenes de la Imprenta en Valencia, fue concedido á D. José Maria Torres, del cuerpo de bibliotecarios archiveros, y en verdad que pocas veces podrá ser más merecida esta distinción. Como la Memoria premiada es muy estensa, el Sr. Torres solo leyó algunos párrafos de la introducción y del final; pero cuando se dé á la estampa su trabajo, admiraran los eruditos las diligentes y afortunadas investigaciones que ha hecho, esclareciendo la importancia que tuvo en Valencia el arte tipográfico en el siglo XV».

3. Pel que fa a la memòria que Torres va enllestir en 1874 i restà inèdita, Serrano (1898-1899: X) afirmà: «Al ocurrir el fallecimiento del autor, nuestro buen amigo, rebuscamos á presencia de su desgraciada viuda sus papeles, para ver si lográbamos salvar de una probable destrucción aquel trabajo que Torres había retirado del Ateneo; y aunque no tuvimos la fortuna de encontrar la copia en limpio, conseguimos recojer algunos borradores y apuntes que, en ciertos casos, nos han servido de luminosa guía para el hallazgo de documentos en los protocolos de notarios á que Torres hace referencia». 
de Teodor Llorente Falcó. Així, l'aleshores director del diari, que començava qualificant l'obra de Martorell com a «precioso incunable», esmentava la descripció que, anys enrere, n'havia fet «nuestro malogrado amigo D. José E. Serrano Morales en su Diccionario de las Imprentas»; per a, ràpidament, al.ludir als nous documents que «hemos podido adquirir de nuestros amigos don José Sanchis Sivera y D. José Rodrigo Pertegás», i que, assegurava, havien sigut localitzats «en el protocolo de Santiago Salvador que se custodia en el Archivo general del Reino» (Antaño, 1913). Els documents en qüestió, que Llorente i Falcó reproduïa, feien referència al contracte d'edició que el mercader Lluís Bertran i el llibreter Pere Tranxer varen establir amb Nicolau Spindeler. La qual cosa permetia concloure a l'autor valencià que:

como se ve por los anteriores documentos, la iniciativa de imprimir Tirant lo Blanch partió de dos entusiastas valencianos, y no del alemán Juan Rix, pues si este la llevó a cabo, fue por cincunstancias especiales (Antaño, 1913).

Així mateix, al cap de pocs mesos, el 9 de novembre de 1913, la premsa valenciana es feia ressò de la proposta llançada pel bibliòfil Josep Ribelles Comín d'iniciar una «Biblioteca Valenciana Popular» dedicada a publicar «un buen caudal de obras antiguas rarísimas [...] para que todos los hijos de la región valenciana aprendan a conocer su país, su historia y su lengua $\gg^{4}$. I entre la vintena de les obres en preparació figurava, com ja podem imaginar, el Tirant lo Blanch.

D’una altra banda, a principis de 1916 l'erudit Francesc Martínez i Martínez, aleshores director de número del Centre de Cultura Valenciana, publicà un opuscle titulat Martín Juan de Galba, coautor de «Tirant lo Blanch» que posava l'èmfasi en la doble autoria de la novel.la. En opinió de Llorente Falcó, que el 6 d'agost d'aquell any havia publicat un nou comentari periodístic -aquesta vegada sota el pseudònim de Mateo-, el treball de Martínez, significativament dedicat «a Don Juan Givanel y Mas», demostrava:

con gran copia de documentos, que el famoso libro de caballerías valenciano Tirant lo Blanch [...] fue obra no sólo de Mossen Johanot Martorell, sino también de Martín Juan de Galba, y ofreciéndonos un trabajo muy curioso acerca de las vicisitudes por que hubo de pasar la impresión de dicho libro y las particularidades de las distintas ediciones que de él se hicieron (Mateo, 1916).

Una teoria que, com sabem, si bé durant dècades tingué gairebé plena acceptació, en els darrers anys ha sigut rebutjada per la majoria de medievalistes, que actualment s'inclinen a pensar que la novel.la és obra d'un únic autor: Joanot Martorell. Llorente Falcó, que en aquell text qualificava Martínez com a «investigador concienzudo y muy sagaz» (Mateo, 1916), també assegurava que el responsable de l'opuscle havia visitat múltiples arxius per tal de documentar-se i realitzar la investigació. I, vertaderament, cal dir que el volumet es cloïa amb un ampli apèndix que recull tots els documents que Martínez degué consultar, o els més significatius, com a mínim.

En darrer lloc, i com a conseqüència de l'interés que, tal com estem comprovant, l'obra de Martorell despertà entre els intel-lectuals valencians de principis del segle XX, cal destacar l'edició -en grafia actualitzada- d'un breu fragment del Tirant lo Blanch que, en setembre de 1928, a l'època denominada com a Segona Renaixença, realitzà l'escriptor Carles Salvador, i que veié la llum a la revista Taula de Lletres Valencianes. Així, Salvador hi reproduí diversos paràgrafs -perta-

4. «Biblioteca Valenciana Popular», Las Provincias (9-XI-1913). 
nyents al capítol 119 de la novel.la- que titulà «Retrat de la Infanta Carmesina»; i els acompanyà d'un extens comentari a peu de pàgina en què no dubtava a qualificar el Tirant com a «obra exemplar» i

un dels millors llibres de la nostra literatura clàssica, [...] influenciada de les literatures italiana i anglesa i sobre tot rep l'influència de la catalana, especialment de les obres de Ramon Llull i del cronista Muntaner (Salvador, 1928: 3).

Cosa que li servia per a afirmar, amb rotunditat -i en resposta a opinions com la que seixanta anys abans havia formulat Josep M. Torres-, «que Martorell escrigué la novel.la en vulgar valencià i que és una fantasia la pròpia dita de que fon traduïda del portugués i abans de la llengua anglesa» (Salvador 1928: 4); que, com hem pogut comprovar, era una de les teories que havia fet fortuna entre alguns lletraferits valencians de la segona meitat del segle XIX. Salvador, en canvi, assegurava que «la novel.la Tirant lo Blanc és catalana -valenciana, restringint l'àrea geogràfica- pel fons i per l'estil». I que en el fragment per ell reproduit «se troben algunes de les característiques [de l'obra]: elegància de llenguatge, minuciositat descriptiva, [i] realisme» (Salvador 1928: 4).

Així mateix, apuntava que les heroïcitats del cavaller Tirant «no entren en els signes de les fades encisadores, sinó que ell i els altres personatges es mouen segons les lleis de la vida humana» (Salvador 1928: 4); i ponderava quina havia estat la participació de Martí Joan de Galba en la redacció de la quarta i darrera part de la novel.la:

El col-laborador de Martorell prou que procura continuar l'estil de les tres primeres parts, peró perd en vis cómica el que guanya en correcció i fluïdesa. M. J. de Galba és un hàbil, magnífic, literat que ni contrafà els personatges, ni refà la tónica realista (Salvador, 1928: 4).

En darrer terme, i per tal de remarcar la seua finalitat divulgativa, Salvador repassava les sis edicions que havia conegut el Tirant lo Blanch, des de la princeps de 1490 fins a la d'Els Nostres Clàssics, que en aquell moment es trobava «en curs de publicació». Amb la qual cosa es feia evident que, en el fons, el que pretenia era invitar el lector, mitjançant el tast d'un breu i atractiu fragment, a endinsar-se en la lectura completa de l'obra de Martorell.

\section{Conclusions}

Com a conclusió, podem afirmar que, esperonats en bona mesura per l'influx de Marià Aguiló, els escriptors valencians de la segona meitat segle XIX i principis del XX realitzaren una contribució positiva a la recuperació, l’estudi i la divulgació d'una novel-la de tan marcades característiques i difícil accés per al lector mitjà com el Tirant lo Blanch. D’una obra que els lletraferits de l'època -i Aguiló en primer lloc-sabien única en el seu gènere, ja que, entre d'altres coses, enaltia la llengua en què fou escrita -tan malmesa durant bona part de l'Edat Moderna i la primera meitat del Vuit-cents- $\mathrm{i}$ la història literària i cultural del poble valencià; i que per això s'esforçaren a valorar i reivindicar, sovint des d'un coneixement molt limitat.

D'aquesta manera, aquells escriptors varen partir de la consciència que el Tirant era una fita de la literatura catalana; una obra a la qual, en no haver sigut editada en català durant els segles XVI-XVIII, fins a l'edició de Marià Aguiló pràcticament només hi tingueren accés bibliotecaris, 
arxivers i erudits. Una circumstància que, a la meua manera de veure-ho, eleva el mèrit dels hòmens i dones que, cent cinquanta anys enrere i vencent tot tipus de dificultats, s'esforçaren per apropar-se al Tirant lo Blanch, analitzar-lo i divulgar-lo. Convertint-nos així a nosaltres, habitants del segle XXI que tenim accés al text de Martorell d'una manera tan ràpida i senzilla, en uns vertaders afortunats.

\section{Bibliografia}

Aguiló, Àngel (1873-1905), «Bibliografia», Libre del valerós e strenu caualler Tirant lo Blanch, Marià Aguiló i Fuster (ed.), Barcelona, Llibreria d'Alvar Verdaguer, pp. IX-XIV.

Aguiló, Marian (1873-1905), «Nota», Libre del valerós e strenu caualler Tirant lo Blanch, Marià Aguiló i Fuster (ed.), Barcelona, Llibreria d'Alvar Verdaguer, pp. V-VII.

ANDRÉs, $\mathrm{D}$ [omènec] (1866), «Breve historia y justos deseos sobre un notable libro», Las Provincias (1-IX-1866).

Antaño, Juan de (1913), «El incunable Tirant lo Blanch», Las Provincias (18-II-1913).

EsCARTí, Vicent J. (2010), «Tirant lo Blanch, Cervantes i més enllà: breu història d'una novel.la de cavalleries», eHumanista, 16, pp. 240-267.

Givanel, Joan (1906), «Necessitat de publicar una Biblioteca clàssica catalana per a la formació del Diccionari», Primer Congrés Internacional de la Llengua Catalana, Barcelona, pp. 541-544.

Llorente, Teodor (1885), «Endressa. Al senyor Don Marian Aguiló», Llibret de versos, València, Teodor Llorente i Ca, editors, pp. 5-12.

Mateo (1916), «De historia. Martín Juan de Galba, coautor de Tirant lo Blanch, por Francisco Martínez Martínez», Las Provincias (6-VIII-1916).

Ribelles, Josep (1915), Bibliografía de la lengua valenciana, Madrid, Imp. de la Rev. de Archivos, Bibliotecas y Museos, vol. I.

RocA, Rafael (2012), «La mitificació vuitcentista del passat medieval: la figura de Jaume I, rei d'Aragó», eHumanista/IVITRA, 2, pp. 271-285.

(2013), «L'inici de la recuperació de Joan Roís de Corella», Afers, 76, pp. 741-757.

(2017), «Tres conferències sobre el Tirant lo Blanch a València (1912, 1919 i 1921)», Tirant, 20, pp. 199-208.

(2018), «Il "Petrarca valenziano": la mitizzazione di Ausiàs March nell’Ottocento», Ausiàs March e il canone europeo, Benedetta Aldinucci i Cèlia Nadal (eds.), Alessandria, Edizioni dell'Orso, pp. 293-310.

(2019), «El procés de localització, difusió i edició del Curial e Güelfa (1876-1901)», Medioevi, 5, pp. 205-223.

S[Alvador], C[arles] (1928), «Del verger classic. Tirant lo Blanc, per J. Martorell - M. J. de Galba (Retrat de la Infanta Carmesina) $\gg$, Taula de Lletres Valencianes, 12, pp. 3-4.

SERRANo, José Enrique (1898-1899), Reseña histórica en forma de diccionario de las imprentas que han existido en Valencia desde la introducción del arte tipográfico en España hasta el año 1868, con noticias bio-bibliográficas de los principales impresores, València, Imprenta de F. Domenech.

TomÀs, Margalida (2012), «Les relacions de Teodor Llorente amb Catalunya i Mallorca», en Teodor Llorente, cent anys després, ed. Rafael Roca, Alacant, Institut Interuniversitari de Filologia Valenciana, pp. 31-71.

[Torres, Josep M.] (1866), «Tirant lo Blanch», Diario Mercantil de Valencia (15-IX-1866). 